\section{Endoscopic stent treatment of a duodenal ulcer perforation}

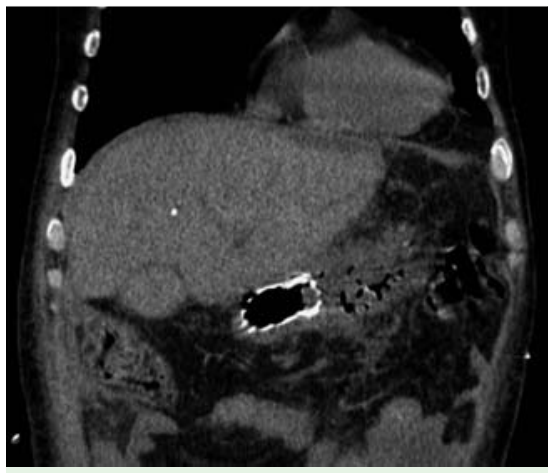

Fig. 1 Computed tomography (CT) scan shows the stent in duodenum with leakage toward the free abdominal cavity.

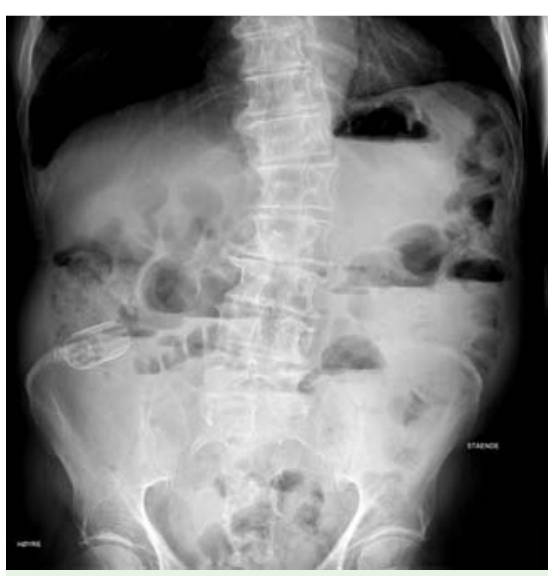

Fig. 2 Radiographic image of the stent in the right fossa with signs of intestinal obstruction.

There are several choices for a reoperation required because of persistent leakage from perforated ulcers or if the perfora- tions are larger than $2-3 \mathrm{~cm}$. Common alternatives are a novel Graham patch closure, Billroth procedure, jejunal serosal patch, and duodenojejunostomy with a Roux-en-Y anastomosis [1,2]. Many of these are complicated surgical procedures which require prolonged general anesthesia.

Our patient, an 81-year-old man, was admitted with a perforated duodenal ulcer and underwent laparotomy 37 hours after onset of symptoms. The $0.5-\mathrm{cm}$, large perforation was closed with two resorbable polyfilament cross-sutures. The patient was then reoperated twice due to persistent leakage, initially with a traditional Graham patch closure and later, aided by a small laparotomy, we used a gastroscope and a guide wire to deliver a duodenal stent, $(90 \times 23$ mm WallFlex, Boston Scientific Norge AS, Asker, Norway) to cover the defect. Unfortunately the stent was damaged during the procedure ( $\bullet$ Fig. 1).

The patient then underwent another gastroscopy. The defective stent was removed, and the perforation, which was estimated to be just over $1 \mathrm{~cm}$ in diameter during the endoscopy, was located and, through the working channel of the gastroduodenoscope, a covered proximal release metal stent with a 90-mm long cover, designed for treatment of malignant strictures in the esophagus $(100 \times 23 \mathrm{~mm}$ Boston Ultraflex), was placed with the distal end in the third part of the duodenum. Following this procedure, the leakage reduced quickly.

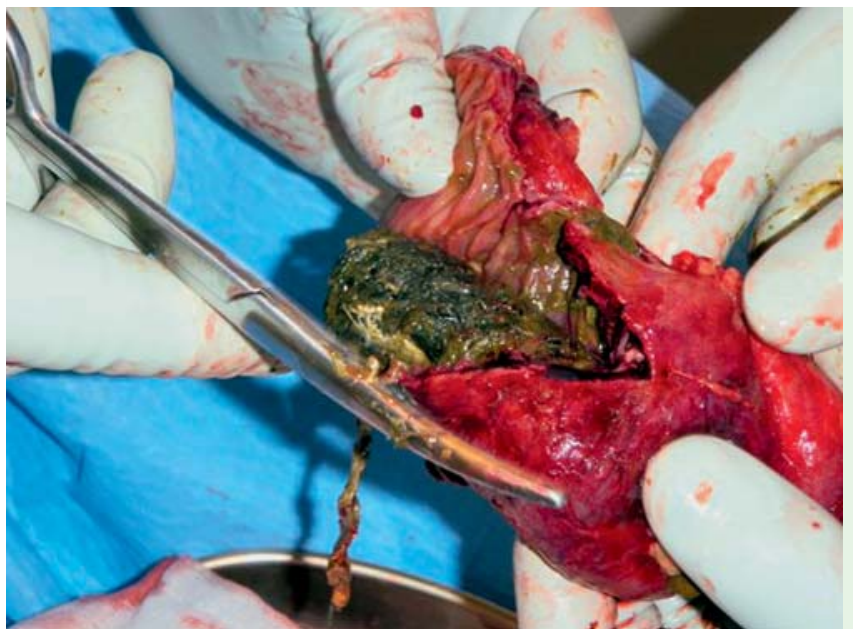

Fig. 3 The stent being removed through an incision in the right fossa.
Migration of covered stents is a common problem with a migration rate of more than $20 \%[3,4]$. At 12 months after the placement, the stent placed in our patient migrated and caused small-bowel obstruction. The patient was again operated, with a McBurney incision in the right fossa. The ileum was resected (approximately $5 \mathrm{~cm}$ ), and the migrated stent removed at the same time ( Figs. 2, 3).

A literature search found no reports of similar attempts using endoscopic stents for duodenal ulcer perforations. We believe that this method can be an alternative for selected patients, combined with percutaneous draining of the abdominal cavity.

\section{Endoscopy_UCTN_Code_TTT_1AO_2AI}

Competing interests: None

\section{T. E. Holm ${ }^{1}$, A. R. Rosseland ${ }^{2}$,}

K. A. E. Lundin ${ }^{3}$, B. I. Røsok ${ }^{2}$,

L. Aabakken ${ }^{3}$, G. Bock¹, G. Lauzikas ${ }^{1}$,

H. Thorne ${ }^{1}$

1 Sykehuset Telemark, Surgical Clinic, Skien, Norway

2 Department of Hepatobiliary, Gastrointestinal and Paediatric Surgery, Oslo University Hospital, Oslo, Norway

3 Department of Medicine, Oslo University Hospital, Oslo, Norway

\section{References}

1 Kobold EE, Thal AP. A simple method for the management of experimental wounds of the duodenum. Surg Gynecolog Obstet 1963; 116: 340

2 Mcllrath DC, Larson RH. Surgical management of large perforations of the duodenum. Surg Clin North Am 1971; 51: 857

3 Jung GS, Song HY, Seo TS et al. Malignant gastric outlet obstructions: treatment by means of coaxial placement of uncovered and covered expandable Nitinol stents. J Vasc Interv Radiol 2002; 13: 275-283

4 Jung GS, Song HY, Kang SG et al. Malignant gastroduodenal obstructions: Treatment by means of a covered expandable metallic stent-initial experience. Radiology 2000; 216: $758-763$

Bibliography

DOI $10.1055 / \mathrm{s}-0030-1256079$

Endoscopy 2011; 43: E60

(c) Georg Thieme Verlag KG Stuttgart · New York . ISSN 0013-726X

Corresponding author

Dr. T. E. Holm

Sykehuset Telemark

Surgical Clinic

Skien

Norway

hthe@sthf.no 